\title{
HB House
}

\section{HENRY RUEDA CORONEL}

Florida International University

\section{Brief:}

The Project is private single family home.

In section, the organization of the House was done as a sequence of three layers:

First: Visitors and guests entrances, service areas, parking, ramps and gardens. The topography was pushed back with a continuous reinforced concrete retaining wall, then filled to create two terraces. Open courtyards on the lateral setbacks, provide cross ventilation and daylight.

Second: Main living areas, as a sequence of open flexible spaces organized between two circulation cores. Glazing and masonry walls, allow views and protects the house against insight from the street.

Four exposed concrete shear walls organize the circulation and movement through the building.

Third: Bedrooms and a family room, all connected by a wide bridge. This layer is clad with limestone to create a composition of big openings and small windows.

In Plan, the House was conceived as an " $\mathrm{H}$ " type. This scheme started as a structural layout with two long shear walls supporting a long span of 16 meters.

\section{Design:}

The building viewed from the front, is an abstract composition of two masses connected through a Vierendeel truss that looks like a monolithic operation of materials with a void, dark space in the middle. A monochromatic range of colors in the façade and a strong graphic horizontality, assures the blending of identity and functions.

The entrance to the home occurs through a complex promenade.

The rear façade expresses three $\neg$ dimensionality. Two rectangular prisms, cantilevered from the main volume, project out to the backyard, into a stable composition appearing as heavy masses.

On a second, discerning view, reveals a contrast of materials, and a dramatic encounter of: poured massive concrete shear walls and glass panels, creating a tension between solid and transparent partitions.

\section{Argument:}

An argument for this Project was: How to understand the "construction site quality" and use it as a language for this building?

The beauty of the construction process, the fantastic moments of the structural phase, the raw materials and simple forms, all disappeared when the surfaces were tiled, cladded or even just painted.

We tried, in this project, to minimize the layering on the basic elements. Keep the essential members of the structure as the grand gesture of the composition. The language of a truss in the main façade, the simplicity of a bare concrete slab.

Space was defined by strong structural movements and imposing members that did not allow changes or variations during the process. A very artisanal and low tech construction culture, proved an advantage to reach a dialogue between the designers, engineers and builders.

These are the challenges in this project and they were achieved after a very refined and detailed process of designing the building systems. Nothing is exposed, everything runs through very shallow drop ceilings or wall cavities.

The House is an exercise on the fundamentals of Technique and Domesticity.

In partnership with: Gabriela Titone, Jorge Preciado, \& Henrique Vera

Assistants: Rockman Vargas \& Raul Cabrera 


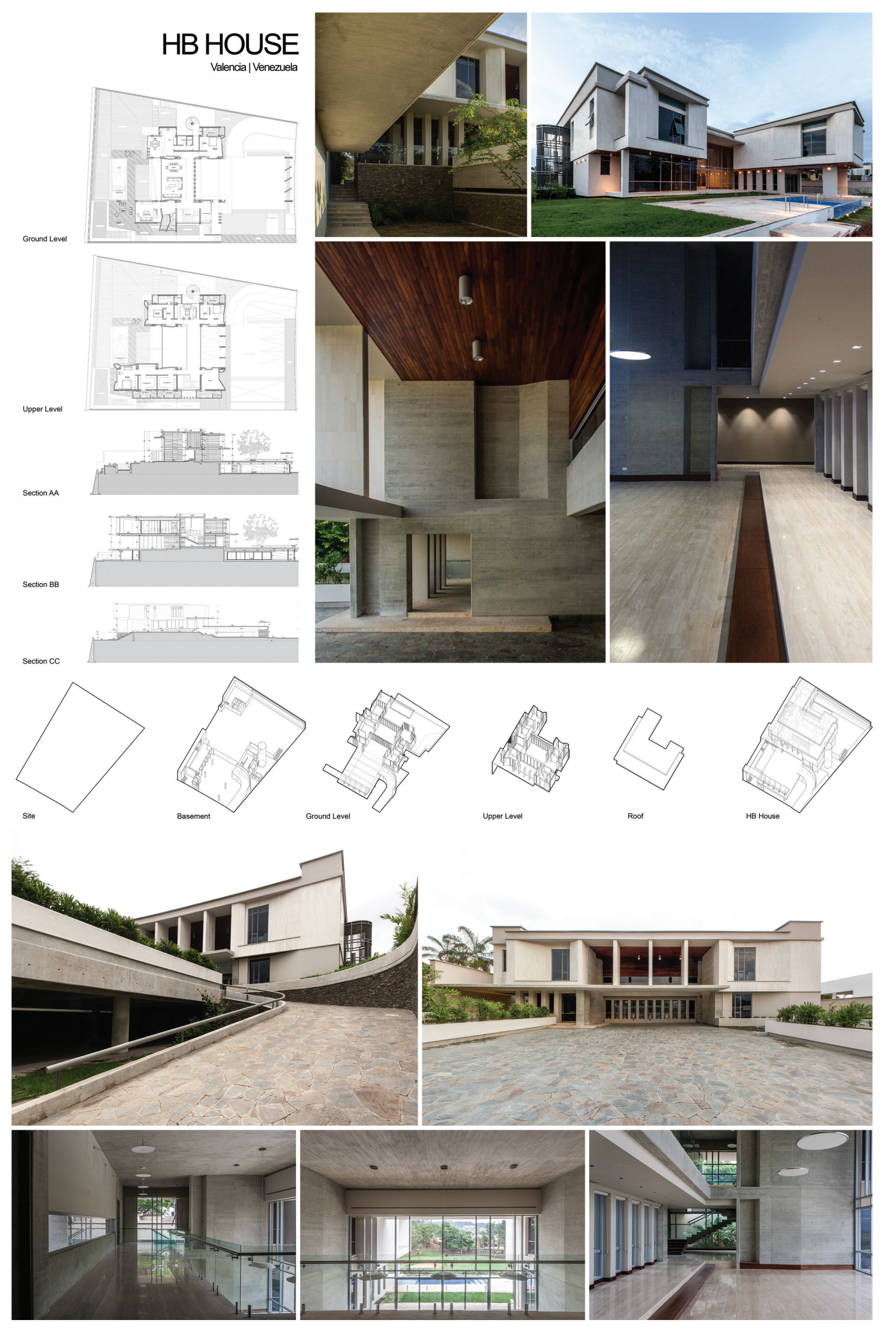

